REFEREN CES

1 Henderson, D. M. (1974). K's and F's. This Journal, 27, No. 4.

2 May, W. E. (1974). The log-books used by ships of the East India Company. This Journal, 27, No. I.

3 Cotter, C. H. (1970). A brief history of nautical logs, to A.D. 1800. This Journal, 23, No. 2.

4 Moore, J. H. (1796). The New Practical Narigator, London.

5 Raper, H. (1840). The Practice of Navigation and Nautical Astronomy, London.

\title{
An Examination of Criticisms of Automatic Radar Plotting Systems and their Advantages in Relation to Manual and Semi-auto Systems
}

\author{
J. C. Herther and F. J. Wylie
}

THE remarks of $\mathrm{Mr}$. Harrison ${ }^{1}$ under the above title demand some further comment. One can certainly agree with his substitution of 'prediction' for 'plotting' but not with his deletion of 'supposed'. The latter begs the whole question whether the operator will be dangerously deceived and this is far from proven. The latter part of his second paragraph is a generality; there will be many combinations of range and speed in which the result will not be satisfactory.

Mr. Harrison implies, although he does not come right out and say so, that errors arising during 'classical' manual plotting are 'operationally' acceptable while the errors in automatic plotting are unacceptable. Such a conclusion is illogical if one is willing to concede that any manual plotting procedure can be automated by the use of a digital computer. To examine this assertion in greater detail one may consider the automatic plotter to be made up of a data extraction section and a data processing section.

The data processing section should cause no difficulty, since anyone familiar with computer usage would admit that any manual plotting method which starts with values of range and azimuth can easily be automated. In fact, the speed and accuracy of the computer allow the use of sophisticated data processing methods such as Kalman filtering, least squares fits \&c. Further, all the data from every scan can be utilized. If desired, even a scheme such as that suggested by section 7 (iii) of Mr. Harrison's paper ${ }^{2}$ could be accomplished.

At this stage, one must confess that one does not know to what computer programme Mr. Harrison is referring. His suggestion that the programme be re-written 'to achieve acceptable operational accuracy', if directed to Sperry, Iotron, Norcontrol and other manufacturers of automatic plotters, implies that he has knowledge of the programmes used, which would seem very doubtful.

The position is, therefore, quite clear with regard to data processing. By handling data in the same manner as in manual plotting equivalent accuracy is obtained, with greater convenience and speed. By using more sophisticated methods greater accuracy can be obtained.

A simple example may help to make this point clear. Figure I shows range and azimuth data on a target derived from the sequential scans of a radar. When 
asked to estimate the course of a target, most observers would draw a line similar to the hatched line in the figure; Mr. Harrison would seem to prefer the solid line extending between two points separated by a specified interval.

Mr. Harrison's remarks concerning data extraction are less open to question. Certainly, errors do exist in the range and azimuth data but their magnitude is debatable. Riggs ${ }^{3}$ states that the error in C.P.A. due to all sources, including $15^{\circ}$ roll, is about $0.15 \mathrm{n} . \mathrm{m}$. at 4 -mile range and about $0.30 \mathrm{n}$.m. at 8 miles. In other words about 4 per cent of range. Without ship motion the errors are about half as large as those given. Mr. Harrison seems to think that larger errors are more likely. Regardless of their magnitude, however, they exist equally in both manual and automatic systems.

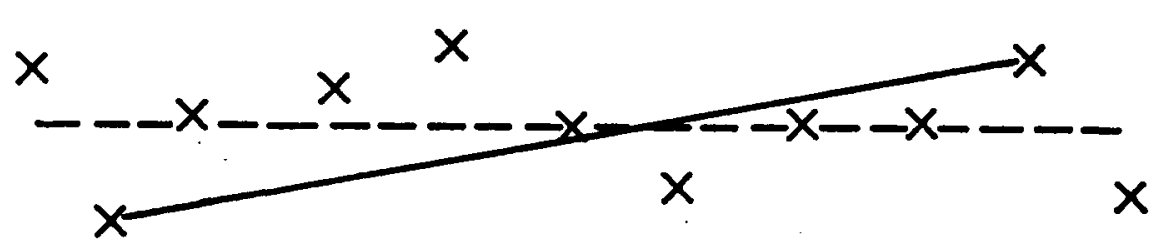

FIG. I

Mr. Harrison quotes the results obtained by Shuffleton and Evans to suggest that target glint causes an increase in C.P.A. errors from 3 per cent of range to 9 per cent. This should not be considered to be a fundamental limitation however, since the centre of gravity of the echo can readily be determined by automatic means.

Finally, Mr. Harrison's claim that systems 'using current equipment and practice will only score $3 \circ$ per cent' likelihood that the predicted C.P.A. will be accurate to \pm 1 mile has no apparent basis. An examination of equipment at present in the field would indicate a significantly better performance. There is also reason to believe that the performance will improve during the next few years.

\title{
REFEREN CES
}

1 Harrison, A. (1974). This Journal, 27, 268.

2 Harrison, A. $(1972)$. 'The risk of error in predicted CPA'. IEE/IERE Conference, 1972.

3 Riggs, R. F. (1974). 'The effects of sensor errors in certain marine collision avoidance and threat assessment systems'. Navigation (U.S.), $21,16$.

\section{Plotter Display Philosophy}

\author{
R. G. Rinaldi \\ (IBM Maritime Applications Systems)
}

IN Captain F. J. Wylie's article, 'Maritime radar automatic plotter display philosophy' in the July 1974 issue of the Journal, he states that the IBM Maritime Application Bridge System (MABS) tracks only six targets for collision assessment 